\title{
Single-Incision Laparoscopic Cholecystectomy with Conventional Instruments: A Surgeon's Initial Experience
}

\author{
Mehmet Zafer Sabuncuoglu1 ${ }^{*}$, Aylin Sabuncuoglu2, Isa Sozen ${ }^{3}$, Gulsum Tozlu1, \\ Mehmet Fatih Benzin', Recep Cetin' \\ ${ }^{1}$ Department of General Surgery, Faculty of Medicine, Suleyman Demirel University, Isparta, Turkey \\ ${ }^{2}$ Anesthesia and Critical Care Unit, Isparta State Hospital, Isparta, Turkey \\ ${ }^{3}$ Genel Surgery Department, Ankara Numune Research and Education Hospital, Ankara, Turkey \\ Email: ${ }^{*}$ drmehmetzafer@yahoo.com
}

Received 13 May 2014; revised 10 June 2014; accepted 5 July 2014

Copyright (C) 2014 by authors and Scientific Research Publishing Inc.

This work is licensed under the Creative Commons Attribution International License (CC BY).

http://creativecommons.org/licenses/by/4.0/

(c) (i) Open Access

\section{Abstract}

Purpose: Since the early 1990s, laparoscopic cholecystectomy has become the gold standard for cholecystectomy. Single-incision laparoscopic surgery (SILS) is a rapidly evolving field as a bridge between traditional laparoscopic surgery and natural orifice transluminal endoscopic. The results are presented here of a single surgeon's initial experience with single-incision laparoscopic cholecystectomy with conventional laparoscopic instruments through his first 11 cases. Materials and Methods: A single curved intra-umbilical $25-\mathrm{mm}$ incision was made by pulling out the umbilicus. A 12-mm trocar was placed through an open approach, and the abdominal cavity was explored with a 10-mm laparoscope. One $10-\mathrm{mm}$ and one $5-\mathrm{mm}$ port were inserted laterally from the laparoscope port. Dissection was performed using a dissector, which was not articulated. The gallbladder was investigated with an Endograsper, which was not articulated either. The hilum was dissected, and the cystic duct and artery were clipped and divided. Results: The patients are comprised of 9 females and 2 males with a mean age of 43.3 years and mean body mass index (BMI) of $27.6 \mathrm{~kg} / \mathrm{m}^{2}$. Open cholecystectomy was not required. The mean operative time was $69.9 \mathrm{~min}$. Length of stay was only one day. All procedures were completed successfully without any perioperative or postoperative complications. In all cases, there was no need to extend the skin incision. Postoperative follow-up did not reveal any umbilical wound complications. The cosmetic results were scored as excellent by all patients. Conclusion: These results suggest that single-incision laparoscopic cholecystectomy is feasible, safe and effective and a promising alternative method to four-port and SILS-port laparoscopic cholecystectomy and as scarless abdominal surgery for the treatment of some patients with gallbladder disease with standard laparoscopic instruments.

${ }^{*}$ Corresponding author.

How to cite this paper: Sabuncuoglu, M.Z., Sabuncuoglu, A., Sozen, I., Tozlu, G., Benzin, M.F. and Cetin, R. (2014) SingleIncision Laparoscopic Cholecystectomy with Conventional Instruments: A Surgeon's Initial Experience. Surgical Science, 5, 299-305. http://dx.doi.org/10.4236/ss.2014.57050 


\section{Keywords}

\section{Laparoscopic Cholecystectomy, Single Incision, Minimal Invasion, Gallbladder Diseases, Complications}

\section{Introduction}

The first laparoscopic cholecystectomy was performed by Erich Mühe in the County Hospital of Böblingen, Germany, on September 12th, 1985. Mühe described designing and constructing his own laparoscope, called the Galloscope, and utilizing it before the era of video assistance. In fact, his technique, especially maintaining pneumoperitoneum proved to be so cumbersome that after performing the first six true laparoscopic cholecystectomies he abandoned the optically guided transumbilical approach under pneumoperitoneum for a single 3-cm subcostal incision approach where the gallbladder was removed under direct visualization [1] [2]. In the following 23 years, Mühe have witnessed many competitive approaches to minimize the invasiveness of laparoscopic cholecystectomies with surgeons developing new instruments and techniques to decrease postoperative pain and improve cosmesis [3] [4]. Traditionally, laparoscopic cholecystectomy (LC) has involved four ports. Many laparoscopic techniques have been developed using this 4-port LC, and it has become possible to perform these techniques safely. Since the introduction of laparoscopic cholecystectomy as the gold standard procedure to remove the gallbladder, many surgeons have attempted to reduce the number and size of ports in laparoscopic cholecystectomy to decrease parietal trauma and improve cosmetic results. Although it is hard to improve on laparoscopic cholecystectomy, the arrival of single-incision or single-port access surgery may allow this.

These efforts are some of the fundamentals of the natural orifice transluminal endoscopic surgery (NOTES) approach [5]-[8] which removes transabdominal incisions completely, but NOTES is technically challenging and current instruments need to be further improved. As a bridge between traditional laparoscopic surgery and NOTES, the recent focus has been on the development of single-incision laparoscopic surgery (SILS) to further minimize the invasiveness of laparoscopic surgery by reducing the number of incisions.

Single-incision laparoscopic surgery has been performed for simple gynecological procedures such as tubal ligation for many years. This concept is now being applied to other areas of surgery and has been described for urological, general, and bariatric surgery. Single-port cholecystectomy emerged from the use of "fewer-port" cholecystectomy, where two or three ports were used to perform the traditional four-port cholecystectomy. Singleport access surgery is the natural evolution of this reduced port concept for cholecystectomy. SILS was described as early as 1992 by Pelosi et al. [5]-[9] who performed a single-puncture laparoscopic appendectomy, and in 1997, by Navarra et al. [6]-[10] who performed a laparoscopic cholecystectomy via two transumbilical trocars and three transabdominal gallbladder stay sutures. The first transumbilical cholecystectomies were described in 1999 [4] [11]. Since then other surgeons have advanced this technique, which goes by many names, such as SILS, single-port access (SPA), single laparoscopic incision transabdominal (SLIT) surgery, etc. [4] [12] [13]. To date, however, little has been formally published regarding single-incision cholecystectomy. SILS can be performed using refinements of existing technology, and surgeons can perform SILS without any new instruments, specific competence, or training. SILS may offer the advantages of reducing postoperative pain, and virtually scarless surgery.

Cuesta et al. reported SILS cholecystectomy, in which two 5-mm ports were introduced through the umbilicus, and a Kirschner wire hook was introduced through the right subcostal area to pullin an upright direction in order to visualize Calot's triangle [14]. Several surgeons have described performing SILS cholecystectomy using three 5-mm ports from the umbilicus [15] [16]. Meanwhile, Merchant et al. also performed SILS cholecystectomy by inserting a Gelport (Applied Medical, Rancho Santa Margarita, CA, USA) to stretch the umbilical fascia incision for easy access with instruments into the abdominal cavity [17]. Furthermore, a technique involving several transumbilical-placed ports for single-incision laparoscopic surgery was newly developed, and SILS cholecystectomy by means of the ASC Triport (Advanced Surgical Concepts, Wicklow, Ireland) had been described successively [18]-[20]. On the other hand, an interesting new instrument named SPIDER (TransEnterix, Inc., Research Triangle Park, NC) for use in single-incision surgery has been developed, and its use in SILS cholecystectomy in an animal experiment has been reported [21]. 
The technique reported here employs a single $2.5-\mathrm{cm}$ horizontally oriented infraumbilical incision to facilitate the placement of three working ports. No extracorporeal stay sutures were used to achieve cephalad retraction of the gallbladder fundus.

\section{Materials and Methods}

\subsection{Patient Selection}

Between August 2010 and April 2013 in Elbistan State Hospital and Suleyman Demirel University, 11 patients underwent single-incision laparoscopic cholecystectomy. The mean age of patients was 43.3 years (range: 29 57 years) and mean body mass index was 27.6 (range, 22 - 33). In all cases, there was no need to extend the skin incision. The average operative time was $69.9 \mathrm{~min}$. The characteristics of the patients and operative data are included in Table 1.

All the procedures were performed by the same surgeon. Patients who underwent this procedure either demonstrated symptomatic cholelithiasis, chronic biliary colic, acute cholecystitis, or gallstone pancreatitis. At the time of informed consent, patients were given the option to undergo either single-incision surgery or a traditional four-port procedure. Patients whose American Society of Anesthesiologists (ASA) classification was 3 or 4 were excluded from evaluation in the study. Patient demographic data as well as height, weight, body mass index (BMI), length of operation, length of stay, perioperative complications, and surgical pathology were recorded on the database under an institutional review board approved analysis.

\subsection{Operative Technique}

The patients were positioned on the operating table in a reverse Trendelenburg, right side up position. A single curved, intra-umbilical, 25-mm incision was made by pulling out the umbilicus. After exposing the fascia, a 12-mm trocar was placed through an open approach and into the peritoneum and insufflated up to $15 \mathrm{mmHg}$ with $\mathrm{CO}_{2}$. The abdominal cavity was explored with a $10-\mathrm{mm}$ laparoscope, then a $5-\mathrm{mm}$ and a $10-\mathrm{mm}$ port were placed through the same umbilical incision but through separate fascial incisions. Each was placed 1-cm laterally from the laparoscope port (Figure 1).

Dissection was performed as a normal retrograde cholecystectomy. The gallbladder hilum was then dissected with a Maryland dissector in the right port to expose the cystic duct and cystic artery which were separately clipped with a 5-mm EndoClip ${ }^{\mathrm{TM}}$ (Covidien, North Haven, CT, USA) and then divided with scissors. For the optimal exposure of the Triangle of Calot the grasper for traction was inserted in the other port. The gallbladder was dissected from the gallbladder fossa with an electrocautery scissors device. The gallbladder was extracted with a standard endocatch bag (Endocatch Gold, $10 \mathrm{~mm}$; Autosuture) through the umbilical site. Careful control of homeostasis was achieved. Finally the trocar site was closed with an absorbable suture, and the umbilicus was restored to its physiological position.

Patients received food orally at $24 \mathrm{~h}$ postoperatively, and were mobilized. All cases were discharged on postoperative day 1 . The postoperative follow-up did not reveal any umbilical wound complications.

\section{Results}

The patients are comprised of 9 females and 2 males with a mean age of 43.3 years (range: 29 - 57 years) and mean BMI of $27.6 \mathrm{~kg} / \mathrm{m}^{2}$ (22 - 33). Open cholecystectomy was not required. The mean operative time was 69.9 $\min (46$ - 110). Length of stay was only one day. All procedures were completed successfully without any perioperative or postoperative complications. In all cases, there was no need to extend the skin incision. Postoperative follow-up did not reveal any umbilical wound complications. The cosmetic results were scored as excellent by all patients. All patients were followed up for more than 6 months and we don't have detect any complications in postoperative follow-up.

\section{Discussion}

Laparoscopic surgery is a well-established alternative to open surgery across disciplines. Although the magnitude of impact varies by procedure, generally the benefits of laparoscopy on postoperative pain, cosmetics, hospital stay, and convalescence are widely recognized. Many surgeons have attempted to reduce the number 
Table 1. Patient characteristics and operative data.

\begin{tabular}{|c|c|c|c|c|c|c|}
\hline & Age (year) & Sex & BMI & Previous history & History of cholecystitis & Operation time (min) \\
\hline 1 & 29 & $\mathrm{~F}$ & 22 & None & + & 110 \\
\hline 2 & 57 & $\mathrm{~F}$ & 20 & DM & - & 90 \\
\hline 3 & 44 & $\mathrm{~F}$ & 28 & Appendectomy & - & 80 \\
\hline 4 & 49 & M & 32 & None & + & 75 \\
\hline 5 & 33 & $\mathrm{~F}$ & 29 & None & - & 80 \\
\hline 6 & 45 & M & 30 & DM & - & 70 \\
\hline 7 & 40 & $\mathrm{~F}$ & 30 & None & - & 60 \\
\hline 8 & 42 & $\mathrm{~F}$ & 28 & $\mathrm{C} / \mathrm{S}$ & + & 58 \\
\hline 9 & 49 & $\mathrm{~F}$ & 33 & $\mathrm{C} / \mathrm{S}$ & - & 52 \\
\hline 10 & 51 & $\mathrm{~F}$ & 27 & $\mathrm{C} / \mathrm{S}$ & + & 46 \\
\hline 11 & 38 & $\mathrm{~F}$ & 25 & $\mathrm{C} / \mathrm{S}$ & - & 48 \\
\hline
\end{tabular}

Note: C/S: ceserean section. History of cholecystitis “+”. DM: diabetes mellitus. BMI: body mass index.

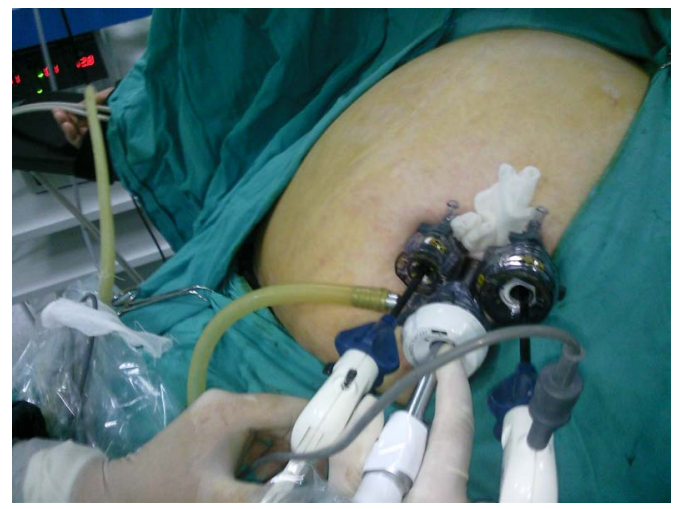

Figure 1. Position of trochars.

and size of ports in laparoscopic surgery to decrease parietal trauma and improve cosmetic results, and recently two innovations have been developed: NOTES, which removes transabdominal incisions completely and SILS, which completes laparoscopic procedures by trocars located at one umbilical incision.

SILS, however, is not a new concept, and was described as early as 1992 by Pelosi et al. [9] who performed a single-puncture laparoscopic appendectomy. In 1997, Navarra et al. published the first case series of 30 patients who underwent what they described as "one-wound laparoscopic surgery” [10]. In recent years, SILS has been focused upon as a bridge between NOTES and traditional laparoscopic surgery, because NOTES is technically challenging and current instruments need to be further improved. SILS, on the other hand enables the application of a wide range of already existing instruments. The main point for reducing the number of incisions is not only the cosmetic advantage but also lowered incision risks, morbidity of bleeding, incisional hernia, and organ damage. Cuesta's method employs a horizontal transumbilical incision and two 5-mm ports. The gallbladder is retracted by a single extracorporeal Kirschner wire, which is manipulated within the abdomen by a proprietary device designed by the authors. The gallbladder is removed by connecting the skin bridge between the two ports [14].

With the global expansion of the use of SILS cholecystectomy, large series of cases have been reported in many institutes. Curcillo et al. reported in their multi-institutional 297-case series that the use of an additional port outside the umbilicus occurred in only 34 cases, and they concluded that SILS cholecystectomy was safe and might serve as an alternative to multiport therapy with fewer scars and better cosmesis [22]. Erbella and Bunch surprisingly reported that their mean operative time was 30 min (range, 22 - 75 min) in 100 consecutive 
SILS cholecystectomy cases [23]. Rivas et al. reported that they had observed surgeons in training and found that experienced laparoscopic surgeons might not need to undergo a steep learning curve, and they concluded that SILS cholecystectomywas becoming the standard procedure for most elective patients with gallbladder disease [24]. Other reports also concluded that SILS cholecystectomy was safe [25] [26].

Out of 252 reported cases in a literature review, 14 (5.6\%) were converted to standard laparoscopic cholecystectomy. The reasons to convert were difficult dissection in nine cases, bleeding from the cystic artery in two, choledochoscopy for common bile duct exploration in two, and failure of trocar insertion in one case. There were five complications in 252 reported cases: one subcutaneous hematoma, one hepatic injury, one bile leakage, one mesenteric injury, and one injury of the right hepatic duct. Operative times in some series have been reported to be on a par with conventional laparoscopic surgery, but the majority of the procedures are lengthy, which may only be justified in patients who have a special cosmetic interest [27].

The real challenge of SILS is to avoid conflict between the operative instruments and the camera, to maintain the pneumoperitoneum and reduce operative stress. As a result of the limited space from using only a single incision, it is difficult for both the surgeon and the assistant to work in the area. Visualization is sometimes not as good. The current commercially available instrumentation is usable but not optimal for this technique. Some authors have suggested percutaneous puncture of the gallbladder for drainage or introduction of suspension hooks for better visualization of Calot's triangle [28] [29]. These manoeuvres, however, may inadvertently increase the chances of bactobilia and lead to perforation of the gallbladder, which leads to an increased risk of bile peritonitis, particularly in the setting of acute cholecystitis.

To avoid these complications some authors have used the fundus of the gallbladder suspended with a loop retractor, which was only tightened with a looped wire for better visualization of Calot's triangle [27]. The use of this retractor enables the surgeon to grasp the gallbladder without injury for visualizing Calot's triangle, without increasing the risk of perforation of the gallbladder.

Some authors have found that working high on the gallbladder is the safest way to dissect the duct and free the artery. In addition, beginning dissection cephalad to the artery and freeing the gallbladder away from the liver allows for greater mobility of the gallbladder and identification of the artery. This is in contrast to the traditional method of working on the cystic duct first, which is often difficult due to the weak tension allowed by the suture retractors and the fact that often the artery is found to be anterior to the duct. Working cephalad to this, similar to a "top-down" approach on the gallbladder, seems to clear up this unusual anatomy. Of course any difficulty should prompt the surgeon to convert to a two- or four-port procedure.

The results of the current study are similar to those previously presented in literature. Over the course of this series, our operative time improved from an average of $93 \mathrm{~min}$ for the first third of the cases to an average of 75 min for the second third of the cases and to just $60 \mathrm{~min}$ for the final case. Retraction sutures were not used in any of the cases. Though this technique allows for appropriate visualization of the "critical view," a "top down" approach was never attempted and would likely be technically difficult to accomplish safely. Only traditional laparoscopic instruments were used in the cases of the current study (Figure 2).

LC has reached an important turning point with the development of single-incision laparoscopic surgery. Most reported techniques utilize a special purpose-made access port and articulating instruments, rendering the procedure costly and difficult to learn. This article documents the feasibility of single-incision laparoscopic cholecystectomy and provides a stepwise description of the SILS cholecystectomy technique using all straight instruments without the need for a special port. The clinical advantages of this approach may eventually require a randomized controlled trial to compare it with conventional laparoscopic cholecystectomy. The major advantage of this method is improved cosmetics, without any visible abdominal scars. The disadvantages of SILS include the conflict between the operative instruments, and the camera and the smaller degree of instrument triangulation compared to that of conventional laparoscopic surgery. Despite the limitations of SILS, we were able to perform our operation in seven cases. All procedures were completed successfully within a reasonable time (Figure 3).

\section{Conclusion}

In conclusion, we have documented the feasibility of single-incision laparoscopic cholecystectomy with standard laparoscopic instruments. The operative outcomes were acceptable. LC has reached an important turning point with the development of single-incision laparoscopic surgery. Further efforts and research will bring about 


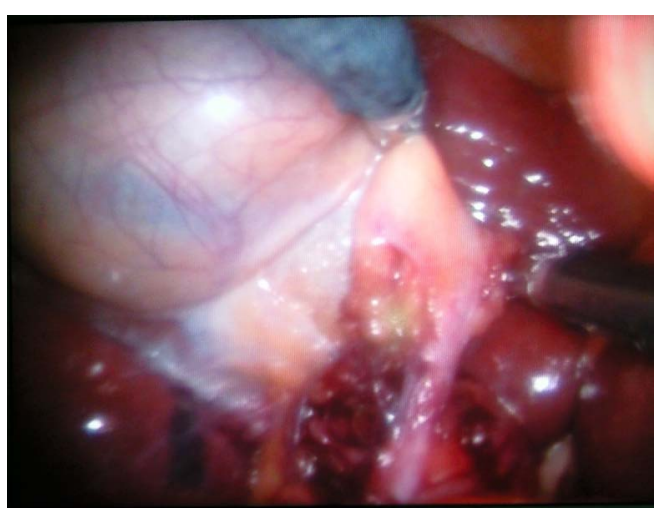

Figure 2. Critical view of calot triangle.

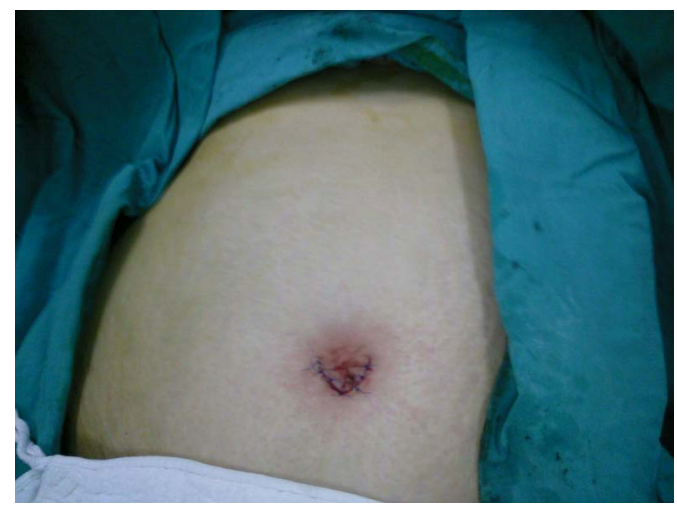

Figure 3. Postoperative view of incision.

improvements in SILS cholecystectomy. The technique and technology for this are still in their infancy but are making rapid progress. This procedure is a promising alternative method to shorten the learning curve, and is a safe and cost-effective SILS cholecystectomy technique, with scarless abdominal surgery, for the treatment of some patients with gallbladder disease with conventional instruments. Further studies need to be conducted comparing morbidity with that of traditional laparoscopy. Cosmetic outcomes are certainly excellent and may drive the overall use of this technology in the future.

\section{References}

[1] Reynolds Jr., W. (2001) The First Laparoscopic Cholecystectomy. JDLS, 5, 89-94.

[2] Mühe, E. (1992) Long-Term Follow-Up after Laparoscopic Cholecystectomy. Endoscopy, 24, 754-758. http://dx.doi.org/10.1055/s-2007-1009119

[3] Kimura, T., Sakuramachi, S., Yoshida, M., et al. (1998) Laparoscopic Cholecystectomy Using Fine-Caliber Instruments. Surgical Endoscopy, 12, 283-286. http://dx.doi.org/10.1007/s004649900654

[4] Piskun, G. and Rajpal, S. (1999) Transumbilical Laparoscopic Cholecystectomy Utilizes No Incisions outside the Umbilicus. Journal of Laparoendoscopic \& Advanced Surgical Techniques, 9, 361-364. http://dx.doi.org/10.1089/lap.1999.9.361

[5] Asakuma, M., Perretta, S., Allemann, P., Cahill, R., Con, S.A., Solano, C., Pasupathy, S., Mutter, D., Dallemagne, B. and Marescaux, J. (2009) Challenges and Lessons Learned from NOTES Cholecystectomy Initial Experience: A Stepwise Approach from the Laboratory to Clinical Application. Journal of Hepato-Biliary-Pancreatic Surgery, 16, 249254. http://dx.doi.org/10.1007/s00534-009-0089-3

[6] Bessler, M., Stevens, P.D., Milone, L., Parikh, M. and Fowler, D. (2007) Transvaginal Laparoscopically Assisted Endoscopic Cholecystectomy: A Hybrid Approach to Natural Orifice Surgery. Gastrointestinal Endoscopy, 66, 12431245. http://dx.doi.org/10.1016/j.gie.2007.08.017

[7] Reddy, N. and Rao, P. (2004) Per Oral Transgastric Endoscopic Appendectomy in Human. Abstract Presented at 45th Annual Conference of the Society of Gastrointestinal Endoscopy of India, Jaipur, 28-29 February 2004. 
[8] Marescaux, J., Dallemagne, B., Perretta, S., Wattiez, A., Mutter, D. and Coumaros, D. (2007) Surgery without Scars: Report of Transluminal Cholecystectomy in a Human Being. Archives of Surgery, 142, 823-826. http://dx.doi.org/10.1001/archsurg.142.9.823

[9] Pelosi, M.A. and Pelosi III, M.A. (1992) Laparoscopic Appendectomy Using a Single Umbilical Puncture (Minilaparoscopy). Journal of Reproductive Medicine, 37, 588-594.

[10] Navarra, G., Pozza, E., Occhionorelli, S., Carcoforo, P. and Donini, I. (1997) One-Wound Laparoscopic Cholecystectomy. British Journal of Surgery, 84, 695. http://dx.doi.org/10.1002/bjs.1800840536

[11] Bresadola, F., Pasqualucci, A., Donini, A., Chiarandini, P., Anania, G., Terrosu, G., Sistu, M.A. and Pasetto, A. (1999) Elective Transumbilical Compared with Standard Laparoscopic Cholecystectomy. European Journal of Surgery, 165, 29-34. http://dx.doi.org/10.1080/110241599750007478

[12] Podolsky, E.R., Rottman, S.J., Poblete, H., King, S.A. and Curcillo, P.G. (2009) Single Port Access (SPATM) Cholecystectomy: A Completely Transumbilical Approach. Journal of Laparoendoscopic \& Advanced Surgical Techniques, 19, 219-222. http://dx.doi.org/10.1089/lap.2008.0275

[13] Langwieler, T.E., Nimmesgern, T. and Back, M. (2009) Single-Port Access in Laparoscopic Cholecystectomy. Surgical Endoscopy, 23, 1138-1141. http://dx.doi.org/10.1007/s00464-009-0389-3

[14] Cuesta, M.A., Berends, F. and Veenhof, A.A.F.A. (2008) The "Invisible Cholecystectomy”: A Transumbilical Laparoscopic Operation without a Scar. Surgical Endoscopy, 22, 1211-1213. http://dx.doi.org/10.1007/s00464-007-9588-y

[15] Gumbs, A.A., Milone, L., Sinha, P. and Bessler, M. (2009) Totally Transumbilical Laparoscopic Cholecystectomy. Journal of Gastrointestinal Surgery, 13, 533-534. http://dx.doi.org/10.1007/s11605-008-0614-8

[16] Petrotos, A.C. and Molinelli, B.M. (2009) Single-Incision Multiport Laparoendoscopic (SIMPLE) Surgery: Early Evaluation of Simple Cholecystectomy in a Community Setting. Surgical Endoscopy, 23, 2631-2634. http://dx.doi.org/10.1007/s00464-009-0369-7

[17] Merchant, A.M., Cook, M.W., White, B.C., Davis, S.S., Sweeney, J.F. and Lin, E. (2009) Transumbilical Gelport Access Technique for Performing single Incision Laparoscopic Surgery (SILS). Journal of Gastrointestinal Surgery, 13, 159-162. http://dx.doi.org/10.1007/s11605-008-0737-y

[18] Langwieler, T.E., Nimmesgern, T. and Back, M. (2009) Single-Port Access in Laparoscopic Cholecystectomy. Surgical Endoscopy, 23, 1138-1141. http://dx.doi.org/10.1007/s00464-009-0389-3

[19] Romanelli, R.J., Mark, L. and Omotosho, P.A. (2008) Single Port Laparoscopic Cholecystectomy with the Triport System: A Case Report. Surgical Innovation, 15, 223-228.

[20] Rao, P.P., Bhagwat, S.M., Rane, A. and Rao, P.P. (2008) The Feasibility of Single Port Laparoscopic Cholecystectomy: A Pilot Study of 20 Cases. HPB, 10, 336-340. http://dx.doi.org/10.1080/13651820802276622

[21] Pryor, A.D., Tushar, J.R. and Di Bernardo, L.R. (2010) Single-Port Cholecystectomy with the TransEnterix SPIDER: Simple and Safe. Surgical Endoscopy, 24, 917-923. http://dx.doi.org/10.1007/s00464-009-0695-9

[22] Curcillo, P.G., Wu, A.S., Podolsky, E.R., Graybeal, C., Katkhouda, N., Saenz, A., et al. (2010) Single-Port-Access (SPA) Cholecystectomy: A Multi-Institutional Report of the First 297 Cases. Surgical Endoscopy, 24, 1854-1860. http://dx.doi.org/10.1007/s00464-009-0856-x

[23] Erbella Jr., J. and Bunch, G.M. (2010) Single-Incision Laparoscopic Cholecystectomy: The First 100 Outpatients. Surgical Endoscopy, 24, 1958-1961. http://dx.doi.org/10.1007/s00464-010-0886-4

[24] Rivas, H., Varela, E. and Scott, D. (2010) Single-Incision Laparoscopic Cholecystectomy: Initial Evaluation of a Large Series of Patients. Surgical Endoscopy, 24, 1403-1412. http://dx.doi.org/10.1007/s00464-009-0786-7

[25] Duron, V.P., Nicastri, G.R. and Gill, P.S. (2011) Novel Technique for a Single-Incision Laparoscopic Surgery (SILS) Approach to Cholecystectomy: Single-Institution Case Series. Surgical Endoscopy, 25, 1666-1671.

[26] Bokobza, B., Valverde, A., Magne, E., Delaby, J., Rubay, R., Bellouard, A., et al. (2010) Single Umbilical Incision Laparoscopic Cholecystectomy: Initial Experience of the Coelio Club. Journal of Visceral Surgery, 147, e253-e257. http://dx.doi.org/10.1016/j.jviscsurg.2010.07.012

[27] Hirano, Y., Watanabe, T., Uchida, T., Yoshida, S., Tawaraya, K., Kato, H. and Hosokawa, O. (2010) Single-Incision Laparoscopic Cholecystectomy: Single Institution Experience and Literature Review. World Journal of Gastroenterology, 16, 270-274. http://dx.doi.org/10.3748/wjg.v16.i2.270

[28] Tacchino, R., Greco, F. and Matera, D. (2009) Single-Incision Laparoscopic Cholecystectomy: Surgery without a Visible Scar. Surgical Endoscopy, 23, 896-899. http://dx.doi.org/10.1007/s00464-008-0147-y

[29] Ersin, S., Firat, O. and Sozbilen, M. (2010) Single-Incision Laparoscopic Cholecystectomy: Is It More than a Challenge? Surgical Endoscopy, 24, 68-71. http://dx.doi.org/10.1007/s00464-009-0543-y 
Scientific Research Publishing (SCIRP) is one of the largest Open Access journal publishers. It is currently publishing more than 200 open access, online, peer-reviewed journals covering a wide range of academic disciplines. SCIRP serves the worldwide academic communities and contributes to the progress and application of science with its publication.

Other selected journals from SCIRP are listed as below. Submit your manuscript to us via either submit@scirp.org or Online Submission Portal.
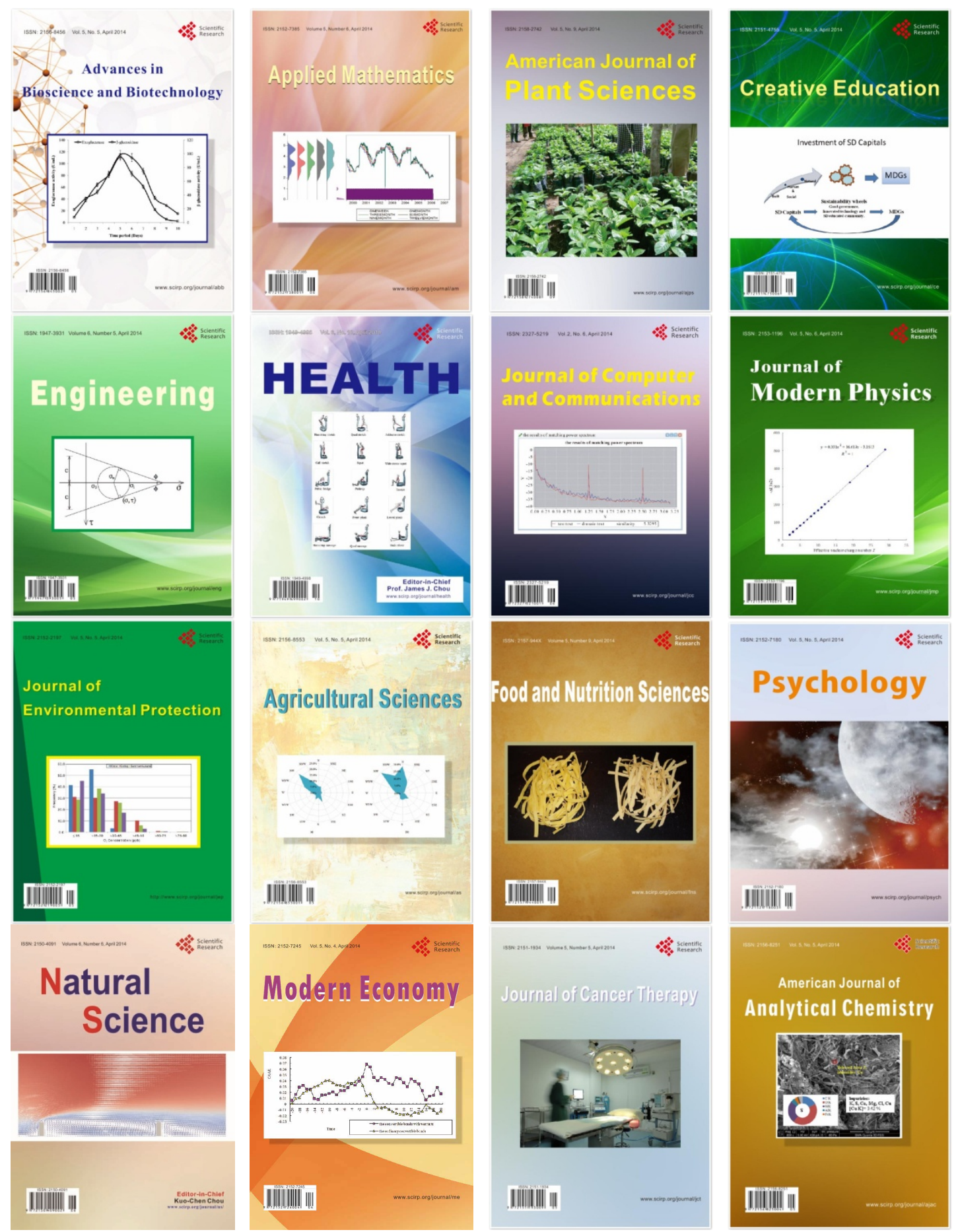